MIRELA DANUBIANU ${ }^{1}$, STĂNICA ANCA MARIA ${ }^{2}$

\title{
STUDY OF IMPROVING THE CUSTOMER RELATIONSHIP MANAGEMENT BY DATA MINING APPLICATIONS
}

\author{
1 "Stefan cel Mare" University of Suceava, \\ 113, Universitatii str., Suceava, Romania, \\ tel: +40230524801, E-mail:mdanub@eed.usv.ro \\ 2 "Alexandru Ioan Cuza” University of Iasi, \\ 11, Carol I str., 700506, Iasi, Romania, \\ E-mail: anca.stanica@yahoo.com
}

\begin{abstract}
Companies must survive in a market, where are a lot of products and competitors which compete to gain the customers. In a such market there are some factors which influences the growing of the complexity of customer relationships. Some of these factors are: the compression of the marketing cycle times, the increasing of marketing costs, the avalanche of new products offering and the existence of niche competitors. The companies must react quickly to the challenges of these factors, reaction which consist in the right offer to the right person at the right time trough the right channel.

CRM involves new ways of interacting with the customers which promises higher returns on investments for businesses by enhancing customer-oriented processes such as sales, marketing, and customer service. Data mining- techniques for automate detecting of relevant patterns in databases- helps companies build personal and profitable customer relationships by identifying and anticipating the needs of customers throughout the customer lifecycle.
\end{abstract}

Keywords: data mining applications, customer relationship management, knowledge discovery in databases.

\section{INTRODUCTION}

The economic environment of the last years has dramatically modified, and the way in which companies interact with their customers has changed also, because in the actual conditions a customer stability is no longer guaranteed. Consequently, a company must understand they customers better, and must quickly respond to their wants and needs. Moreover, to succeed,, it must be proactive and anticipate what a customer desire”. [K. Tearling]

Data mining - techniques for automate detecting of relevant patterns in databases- helps businesses sift through layers of seemingly unrelated data for meaningful relationships. Data mining uses statistical and machine learning techniques to build models that predict customer behavior. For the best results the mining process must be integrated with commercial data warehouses, and it must presents the models in a relevant way for business users.

\section{CRM}

Customer relationship management (CRM) is a process that manages the interactions between a company and its customers. Also, it can be defined as an enterprise customer-centric approach that uses different techniques to understand and influence consumer behavior. The goal of CRM is to maximize relationships with the customers over their lifetime. It entails focusing all aspects of the business, from marketing, sales, operations and service, to establishing and sustaining mutually beneficial customer relations.

In the real world, acquiring, building, and retaining customers are becoming top priorities. For many companies, the quality of their customer relationships provides their competitive edge over other businesses. Companies are beginning to realize that surviving an intensively competitive and global marketplace requires closer relationships with customers.

In turn, enhanced customer relationships can boost profitability in three ways: by attracting more suitable customers, by generating profits through cross-selling and up- selling activities, and by extending profits through customer retention. 


\section{DATA MINING}

Data mining is the exploration and analysis, by automatic or semiautomatic means, of large quantities of data in order to discover meaningful patterns and rules[3]. So, data mining is defined as the process of extracting interesting and previously unknown information from data, and it is widely accepted to be a single phase in a complex process known as Knowledge Discovery in Databases (KDD). This process consist of a sequence of the following steps [12]: data cleaning, data integration, data selection, data transformation, data mining, pattern evaluation and knowledge presentation.

Thus data mining is the search of valuable information in large volumes of data. This combine the efforts of human, who design the databases, describe the problems and set the goals, and computers who process the data looking for patterns that match this goals.

Data mining sits at the common frontiers of several fields including database systems, artificial intelligence, statistics, machine learning, pattern recognition or data visualization. In order to ensure that the extracted information generated by the data mining algorithms is useful, additional activities are required, like incorporating appropriate prior knowledge and proper interpretation of the data mining results.

The basic objective is to construct a model for one situation in which the answer or output is known and then apply that model to another situation in which the answer or output is desired. The best applications of the above techniques are integrated with data warehouses and other interactive, flexible business analysis tools.

\section{DATA MINING IN THE CRM PROCESS}

In general, CRM promises higher returns on investments for businesses by enhancing customer-oriented processes such as sales, marketing, and customer service.

Data mining helps companies build personal and profitable customer relationships by identifying and anticipating the needs of customers throughout the customer lifecycle. Data mining can help to reduce information overload and improve decision making. This is achieved by deriving and refining useful knowledge through a process of searching for relationships and patterns from the extensive data collected by organizations. The extracted information is used to predict, classify, model, and summarize the data. Data mining technologies, such as rule induction, neural networks, genetic algorithms, fuzzy logic, and rough sets, are used for classification and pattern recognition in many industries [4][10][11].

Data mining builds models of customer behavior by using statistical and machine- learning techniques.

Hence, data-mining applications can help companies to identify market segments containing customers with high profit potential, by searching for patterns among the different variables that serve as effective predictors of purchasing behaviors. Marketers can then design and implement campaigns that will enhance the buying decisions of a targeted segment. To facilitate this activity, marketers feed the data-mining outputs into campaign management software that focuses on the defined market segments.

Regarding the three ways of boosting profitability discussed in the first section, the data mining techniques may be used as following.

Data mining can help firms understand which customers are most likely to purchase specific products and services, thus enabling businesses to develop targeted marketing programs for higher response rates and better returns on investment.

Businesses can increase their value proposition by offering additional products and services that are actually desired by customers, thereby raising satisfaction levels and reinforcing purchasing habits.

Data-mining techniques can identify which customers are more likely to defect and why a company can use this information to generate ideas that allow them to maintain these customers.Moreover, there are additional ways in which data mining supports CRM initiatives.

Data mining helps database marketers develop campaigns that are closer to the targeted needs, desires, and attitudes of their customers. If the necessary information resides in a database, data mining can model a wide range of customer activities. The key objective is to identify patterns that are relevant to current business problems. For example, data mining can help answer questions such as "Which customers are most likely to acquire a certain tourist's service?" Answering these types of questions can boost customer retention and campaign response rates, which ultimately increases sales and returns on investment.

The growth strategy of businesses depends heavily on acquiring new customers, which may require finding people who have been unaware of various products and services, who have just entered specific product categories (for example, new parents and the diaper category), or who have purchased from competitors. Although experienced marketers often can select the right set of demographic criteria, the process increases in difficulty with the volume, pattern complexity, and granularity of customer data. Highlighting the challenges of customer segmentation has resulted in an 
explosive growth in consumer databases. Data mining offers multiple segmentation solutions that could increase the response rate for a customer acquisition campaign. Marketers need to use creativity and experience to tailor new and interesting offers for customers identified through data-mining operations.

Many marketing organizations have a variety of methods to interact with current and prospective customers. The process of optimizing a marketing campaign establishes a mapping between the organization set of offers and a given set of customers that satisfies the characteristics and constraints of a campaign, defines the marketing channels to be used, and specifies the relevant time parameters. Data mining can elevate the effectiveness of campaign optimization processes by modeling the channel- specific responses of customers to marketing offers. The different data mining techniques may be associated with CRM tasks. Table 1 present some of these associations.

The ones presented above demonstrate the fact that there is some data mining techniques which application, on the data related to the customers of a company, can lead to an improvement of the different aspects regarding the customers relationships. According to the survey made by the KDNuggets on 138 companies, in 2007 theuse of data mining in CRM took the first place in the top of data mining applications in industry. The results of this survey are presented in Figure 1.Industries/fields where are applied data mining in the past 12 months(2007).

Table 1.

Possible association between data mining techniques and CRM operations

\begin{tabular}{|c|c|}
\hline Data mining technique & CRM operation \\
\hline Association rules & $\begin{array}{r}\text { Information from customer-purchase histories is used to formulate } \\
\text { probabilistic rules for subsequent purchases. }\end{array}$ \\
\hline Decision trees & $\begin{array}{c}\text { Automatically constructed from data, these yield a sequence of step- } \\
\text { wise rules; good for identifying important predictor variables, non- } \\
\text { linear relationships, and interactions among variables }\end{array}$ \\
\hline Genetic algorithms & $\begin{array}{c}\text { Use procedures modeled on evolutionary biology to solve prediction } \\
\text { and classification problems or develop sets of decision rules. }\end{array}$ \\
\hline Neural networks & $\begin{array}{c}\text { Applications that mimic the processes of the human brain; capable of } \\
\text { learning from examples (large training sets of data) to discover } \\
\text { patterns in data }\end{array}$ \\
\hline Query tools & $\begin{array}{c}\text { Provide summary measures such as counts, totals, and averages } \\
\text { Ordinary least-squares regression, logistic regression, discriminant } \\
\text { analysis; used mostly for confirmation of models built by "machine- } \\
\text { learning" techniques }\end{array}$ \\
\hline Visualization tools & $\begin{array}{c}\text { Histograms, box plots, scatter diagrams; useful for condensing large } \\
\text { amounts of data into a concise, comprehensible picture }\end{array}$ \\
\hline
\end{tabular}

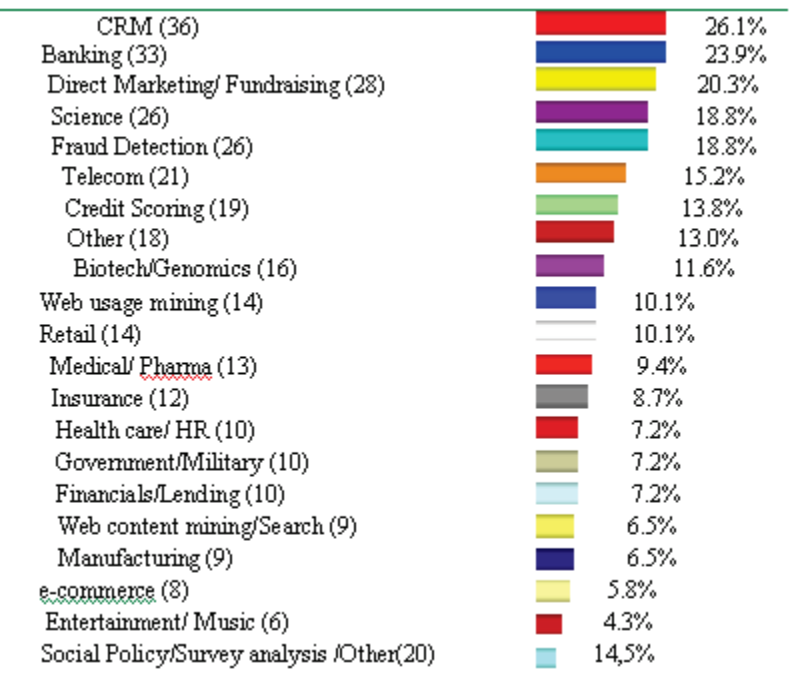

Fig. 1. The results of the 2007 survey of Data mining application in industry (Surce: KDnuggets - Polls - Data Mining Applications by Industry) 


\section{CONCLUSION}

The integration of data mining and CRM have a lot of benefits for the companies, which must understand that some customers are significantly more profitable than others. Data mining can help to identify and target these customers, whose data is buried in massive databases, thereby helping to redefine and reinforce customer relationships.

\section{REFERENCES}

1. Berry, M., Linoff, G., (1997) Data Mining Techniques for Marketing, Sales and Customer Support, John Whiley \&Sons

2. Danubianu M. (2003) Determinarea metodei optime de explorare a datelor pentru un sistem intelligent deevaluare a activită ii în turism, volumul „Tehnologii Informa ionale”, Suceava, pag.156163, ISBN 793-666-059-1

3. Danubianu M.(2005) Determinarea claselor pe baza tehnicii SBA, volumul seminarului "Procesare distribuită”, pag. 86-90, ISBN 973-666-177-6

4. Danubianu M. (2006) Using data mining techniques for decision support systems - Proceedings of the International Conference on Signal/Image Processing and Pattern Recognition -"UkrObraz-2006",pag. 19-22, August 28-31, 2006, Kiev, Ucraina

5. Fleisher, C. S., \& Blenkhom, D. (2003) Controversies in competitive intelligence: The enduring issues. Westport, CT: Praeger.

6. IDC \& Cap Gemini. Four elements of customer relationship management. Cap Gemini White Paper.

7. Kotler, P., Bowen, J., and Makens, J., (1999)Marketing for Hospitality and Tourism, second edition ,Upper Saddle River, NJ: Prentice-Hall,.

8. Olsen, M., Connolly, D., (1999) Antecedents of Technological Change in the Hospitality Industry, Tourism Analysis, Vol. 4, p. 29.

9. Pentiuc., Ghe-St, MORARIU, N. Morariu, M, Pentiuc. L (2001) Intelligent System For Impact Prognosis Of The Economic Decisions At District Level, Advances in Electrical and Computer Engineering ISSN 1582-7445 - Volume 1(18), Number 1(15), 2001

10. Zhao, L. J., \& Zhu, D. (2003). Workflow resource selection from UDDI repositories with mobile agents. Proceedings of Web2003, USA.

11. Zhu, D., Premkumar, G., Zhang, X., \& Chu, C. (2001). Data mining for network intrusion detection: A comparison of alternative methods. Decision Sciences, 32(4), 635-660.

12. Wirth, R. and Hipp, ( 2000) J. CRISP-DM: Towards a standard process model for data mining. In Proceedings of the 4th International Conference on the Practical Applications of Knowledge Discovery and Data Mining, pages 29-39, Manchester, UK.

Надійшла до редакції 25.11.2008p.

MIRELA DANUBIANU - a lecturer in Electrical Engineering and Computer Science at the "Stefan cel Mare" University of Suceava, Suceava, Romania, E-mail: mdanub@eed.usv.ro 